\title{
Volatility Spillovers: Evidence On U.S. Oil Product Markets
}

Bernard Ben Sita, Lebanese American University, Beirut Campus, Lebanon Salah Abosedra, Lebanese American University, Beirut Campus, Lebanon

\begin{abstract}
This paper provides evidence on the lead, the contemporaneous and the lagged transmission mechanism of extreme shocks across energy products. Our findings reveal a weak leadership of crude oil in guiding hedgers against risk that is specific to natural gas whose changes show a weak reliance on changes in crude oil. Moreover, our findings are consistent with the competitive use of energy products. It follows that substitutability characterizes the relationship between heating oil and natural gas when extreme standardized shocks are considered.
\end{abstract}

Keywords: GARCH; Oil products; Natural Gas; Volatility Spillovers

\section{INTRODUCTION}

large number of studies have investigated how shocks in prices of oil products impact the risk transformation on capital markets, the production of goods and services, and the consumption baskets (e.g., Ferson and Harvey, 1993; Hooker, 1999; Hamilton, 2003; Hammes and Wills, 2005; and Driesprong et al., 2008). Despite this larger number of studies, shocks in oil product are still puzzling and their impacts are not well-understood. For instance, Driesprong et al. (2008) found that stock market return underreacts to oil shocks. They rationalized this behaviour using the gradual information diffusion argument of Hong and Stein (1999). According to the underreaction hypothesis, shocks in prices of oil products may show different patterns associated with market perception and investors' bias. Surprisingly, few studies have investigated oil shocks for what they are. This paper takes this venue. It investigates how shocks are transmitted across a spectrum of oil products prices and natural gas price. Understanding how a shock from one oil product price is transmitted to another product price can enhance our understanding of the kind of puzzle envisioned by Driesprong et al. (2008).

Our empirical research ascribes to a strand of studies investigating within the multivariate GARCH model the dynamics of volatility spillovers from one oil product to another (e.g, Lee et al., 1995; Ewing et al., 2002; $\mathrm{Ng}$ and Pirrong, 1996; Pindyck, 2004; Manera et al., 2006; and Lee and Zyren, 2007). However, we differ from these studies in the ways we deal with the transmission mechanism. We use a parsimonious procedure to measure the contribution of one energy product to another energy product conditional variance. While multivariate GARCH models are mostly used in measuring relationships in volatility across assets and markets, they are not always suitable in cases where a distinct effect must be isolated, and a broader perspective of spillovers must be investigated. Our purpose is better served following augmented GARCH models under which information effects are readily examined (e.g., Lamoureux and Lastrapes, 1990; Hwang and Satchell, 2005; Staikouros, 2006; and Han, 2010).

Our statistical significant results can be given economic contents. For instance, we find that extreme standardized shocks in gasoline have reversal leading effects on crude oil, while such a leadership is absent in shocks from crude oil to gasoline. It follows that hedgers or speculators can take the opposite position in either product to improve on their expected return. Additionally, we find that our results on the relationship between natural gas and heating oil are consistent with the competitive use of these products. The two products are linked in volatility regarding future, current and past volatility. Overall, our results on spillovers reveal that variation in oil products has a greater impact on natural gas, while variation in natural gas has no effect on crude oil and gasoline. 
The rest of the paper is organized as follows. The following section presents the econometric analyses and the last section gives some concluding remarks.

\section{EMPIRICAL RESULTS}

We present in this section the data, describe the variables, present the empirical model, and summarize the empirical results.

\section{Data}

We use daily spot price data on crude oil, heating oil, gasoline and natural gas obtained from WTRG Economics. The sample period is from November 1, 1993 to April 20, 2005 for a total of 2,685 observations. Crude oil prices are spot prices of West Texas Intermediate (WTI) in dollars per barrel, natural gas prices are the U.S. natural gas wellhead prices in dollars per thousand cubic feet, gasoline prices are New York harbour conventional gasoline prices in cents per gallon, and heating oil prices are New York harbour No 2 in cents per gallon. Let $P_{i t}$ be the price for $i=c, g, h$, and $n$, then its first logarithmic difference $i R_{i t}=\ln \left(P_{i t} / P_{i t-1}\right)$. Table (1) reports the summary statistics of crude oil price changes denoted as $R_{c t}$, heating oil price changes denoted as $R_{h t}$, gasoline price changes denoted as $R_{g t}$, and natural gas price changes denoted as $R_{n t}$, where $t$ indexes days and monthly, respectively.

Table 1: Summary statistics

\begin{tabular}{|c|c|c|c|c|}
\hline & $R_{c t}$ & $R_{g t}$ & $R_{h t}$ & $R_{n t}$ \\
\hline$\mu \times 100$ & 0.038 & 0.039 & 0.037 & 0.040 \\
\hline$\sigma$ & 0.0247 & 0.0277 & 0.0274 & 0.0602 \\
\hline$\mu(l)$ & -0.200 & -0.165 & -0.334 & -1.273 \\
\hline$\mu(m)$ & 0.181 & 0.121 & 0.241 & 0.875 \\
\hline$s k$ & -0.388 & -0.422 & -0.480 & -1.510 \\
\hline$k s$ & 6.093 & 2.087 & 14.687 & 107.974 \\
\hline$Q\left(r_{i t}\right)$ & 98.591* & $92.272 *$ & 99.494* & $476.993 *$ \\
\hline$Q\left(r_{i t}^{2}\right)$ & $367.458^{*}$ & $269.956 *$ & $1329.074 *$ & $1280.957 *$ \\
\hline
\end{tabular}

The daily price change average is about $.04 \%$ for the four prices but this average is indistinguishable from zero, which is not a surprise. Daily price changes are not Gaussian, as the skewness and kurtosis statistics show. With a standard deviation of $6.02 \%$, the natural gas price volatility is about two times higher than the price volatility of the oil products. Using 252 trading days, the annualized volatility is $39.27 \%, 43.89 \%, 43.50 \%$, and $95.50 \% \%$ for crude oil, gasoline, heating oil and natural gas, respectively. Table 1 also shows that linear and squared returns are jointly auto-correlated at lag 72 . Thus, our empirical models will be guided by these regularities. 


\section{The empirical model}

We assume a Granger-bivariate economic space. We also assume that the covariance between product $i$ and $j$ equals zero. This assumption is consistent with a bivariate GARCH model whose matrix is diagonal. Let $r_{i t}$ be given by $\mu_{t}+z_{i t} h_{i t}^{1 / 2}$, where $\mu_{i t}=a_{i 0}+a_{i 1} r_{i t-1}+a_{i 2} e_{i t-1}+b_{1} f_{t}+b_{i 2} J_{i t}, z_{i t}=e_{i t} / h_{i t}^{1 / 2}$ with $E z_{i t}=0$ and $E z_{i t}^{2}=1, J_{t}=1$ whenever $e_{t}>2 h_{t-1}^{1 / 2}$ and 0 otherwise, $f_{t}$ is a systematic factor that is crude oil return for the refined oil products, $h_{i t}=\omega_{i}+\left(\alpha_{i 1}+\alpha_{i 2} d_{i t-1}\right) e_{i t-1}^{2}+\beta_{i} h_{i t-1}$, and $d_{i t}=1$ whenever $e_{t}<0$ and 0 otherwise. Thus, under the assumption that the conditional variance includes all information relevant to the price considered, the following factor captures excessive shocks in price $i$ that can spill over to product $j$,

$$
\Lambda_{j i, t}=\frac{e_{j t} / h_{j t}^{1 / 2}}{e_{i t} / h_{i t}^{1 / 2}} J_{j t} .
$$

This factor is simple and intuitive. This simplicity is obtained under the assumption that prices $i$ and $j$ are perfectly correlated. This is defendable as prices of oil products are shown to be integrated (e.g., Asche et al., 2003). Since $\Lambda_{j i, t}$ is a relative measure of information idiosyncrasy, $\Lambda_{j i, t}$ could be an indicator of information transmission between product $i$ and $j$. From this perspective, $\Lambda_{j i, t}$ plays the role of an information variable as in Lamoureux and Lastrapes (1990). By inserting it into a TGARCH(1,1), it captures the transmission of shocks from one product to another.

$$
h_{i t}=\omega_{i}+\left(\alpha_{i 1}+\alpha_{i 2} d_{i t-1}\right) e_{i t-1}^{2}+\beta_{i} h_{i t-1}+\delta_{j i,+1} \Lambda_{j i, t+1}+\delta_{j i, 0} \Lambda_{j i, t}+\delta_{j i,-1} \Lambda_{j i, t-1},
$$

where $\omega_{i} \geq 0, \alpha_{i 1} \geq 0, \alpha_{i 2} \geq 0$ under asymmetry and $\alpha_{i 2} \leq 0$ under leverage, $\alpha_{i 3} \leq 0, \beta_{i} \geq 0, \delta_{j i,+1} \leq 0$ as associated with surprises in the leadership, $\delta_{j i, 0} \geq 0$ as associated with the semi-strong form of information efficiency, and $\delta_{j i,-1} \geq 0$ as associated with the under-reaction hypothesis. Equation (2) could be extended with more leads and lags, and additional innovation effects from other oil products.

Equation (2) maximizes all the bivariate possibilities, which are difficult to measure under a bivariate GARCH model. For instance, (2) has a lead, a contemporaneous and a lag subset of the information set. A bivariate GARCH model is often presented in terms of the weak-form of information efficiency. Nevertheless, we don't make the claim that splitting the information set in this way would guarantee a complete representation of all the elements of information set pertaining to the mapping of oil risk.

\section{Findings}

We estimate equation (2) assuming that the error term is t-distributed following Wilhelmsson (2006) who finds that the t-distribution shows better performance in forecasting. For our case, the t-distribution is justified as Table 1 showed that returns are leptokurtic. Table 2 reports the estimates of equation (2) and the mean equation.

We start by giving some statistics on diagnostic tests. We use the distribution and the independence of the linear standardized residuals to check on the fitness of our mean equation, which is given in terms of the first order autoregressive (AR) term, the first-order moving average (MA) term, a measure for a deterministic jump and a measure for pricing effects for refined oil products and natural gas. The Ljung-Box statistic shows that the linear standardized residuals are jointly orthogonal at lag 75 . However, the standardized residuals are not Gaussian, which call for a more sophisticated model. For this paper, we mitigate the leptokurtic effects by estimating the mean and the variance equation under the assumption that the error term follows a t-distribution with unknown parameter $\mathrm{v}$. Table 2 shows that the shape parameter is quite large, which is an indication of how strong is the deviation of the 
residuals from Gaussianity. Moreover, we check that the GARCH model fits well the squared innovations. The Ljung-Box statistic shows again that the squared standardized residual are orthogonal at lag 75 . Thus, our estimates are robust to autocorrelation and heteroskedasticity.

Table 2: Bivariate estimates into a univariate TGARCH model

\begin{tabular}{|c|c|c|c|c|}
\hline & $R_{c t}$ & $R_{g t}$ & $R_{h t}$ & $R_{n t}$ \\
\hline$a_{0} \times 10^{3}$ & -0.085 & 0.202 & 0.341 & 0.530 \\
\hline$b_{1}$ & & $0.786^{*}$ & $0.789 *$ & $0.074 *$ \\
\hline$b_{2}$ & $0.057^{*}$ & $-0.007^{*}$ & -0.001 & 0.001 \\
\hline$a_{1}$ & 0.019 & $0.972 *$ & 0.006 & $-0.397 *$ \\
\hline$a_{2}$ & 0.022 & $-0.997 *$ & -0.006 & $0.457^{*}$ \\
\hline $\bar{\sigma}_{i c}$ & & 0.020 & 0.016 & 0.078 \\
\hline $\bar{\sigma}_{i g}$ & 0.022 & & 0.018 & 0.035 \\
\hline $\bar{\sigma}_{i h}$ & 0.031 & 0.020 & & 0.039 \\
\hline $\bar{\sigma}_{i n}$ & 0.022 & 0.020 & 0.016 & \\
\hline$\delta_{i c,+1} \times 10^{5}$ & & 0.005 & $0.007 *$ & -0.130 \\
\hline$\delta_{i c, 0} \times 10^{5}$ & & -0.007 & $0.026^{*}$ & $-0.102 *$ \\
\hline$\delta_{i c,-1} \times 10^{5}$ & & 0.012 & -0.010 & $-0.088 *$ \\
\hline$\delta_{i g,+1} \times 10^{5}$ & $-0.033^{*}$ & & 0.001 & -0.032 \\
\hline$\delta_{i g, 0} \times 10^{5}$ & -0.024 & & $0.005^{*}$ & -0.052 \\
\hline$\delta_{i g,-1} \times 10^{5}$ & 0.045 & & -0.002 & $0.081^{*}$ \\
\hline$\delta_{i h,+1} \times 10^{5}$ & -0.035 & 0.010 & & $-0.068 *$ \\
\hline$\delta_{i h, 0} \times 10^{5}$ & -0.023 & -0.018 & & $0.141^{*}$ \\
\hline$\delta_{i h,-1} \times 10^{5}$ & -0.018 & 0.007 & & $-0.079 *$ \\
\hline$\delta_{i n,+1} \times 10^{5}$ & 0.005 & -0.022 & $-0.024^{*}$ & \\
\hline$\delta_{i n, 0} \times 10^{5}$ & 0.002 & -0.014 & 0.041 & \\
\hline$\delta_{i n,-1} \times 10^{5}$ & -0.001 & -0.003 & -0.027 & \\
\hline$v$ & 19.999 & 9.967 & 19.999 & 19.702 \\
\hline$Q_{75}\left(z_{i t}\right)$ & 98.478 & 90.176 & 72.299 & 78.512 \\
\hline$Q_{75}\left(z_{i t}^{2}\right)$ & 62.396 & 88.211 & 32.968 & 6.133 \\
\hline$s k$ & -0.783 & 0.138 & 0.872 & 1.827 \\
\hline$k s$ & 6.541 & 6.643 & 9.325 & 38.142 \\
\hline
\end{tabular}


The estimates of Table 2 show that crude oil return enters the pricing equation of refined products smoothly. However, crude oil is a weak factor for natural gas. Deterministic jump effects tend to increase the crude oil drift, while they tend to decrease the gasoline drift. The GARCH parameters are summarized in terms of the unconditional volatility, which is obtained as the square root of $\bar{\sigma}_{i j}=\omega /\left(1-\alpha_{1}-\alpha_{2} \times 0.5-\beta\right)$.

The unconditional volatility shows the contribution of the price product $j$ to that of product $i$. Four worthwhile results are obtained. First standardized extreme shocks in heating oil have the greatest impact on crude oil volatility. Second, standardized extreme shocks in crude oil, heating oil and natural gas have neutral effects on gasoline volatility. Third, standardized extreme shocks in gasoline have the greatest impact on heating oil volatility. Fourth, standardized extreme shocks in crude oil have the greatest impact on natural gas volatility.

The bivariate relationships are given in terms of leadership, contemporaneity and procrastination in $\Lambda_{j i, t+1}$, $\Lambda_{j i, t}$ and $\Lambda_{j i, t-1}$, respectively. Table 2 uncovers unidirectional leadership of gasoline inducing reversal change in crude oil, which in its turn induces a positive leadership in heating oil. In contrast, there is a bidirectional leadership in heating oil and natural gas. In addition to leadership relationships, Table 2 shows that extreme standardized shocks in gasoline spill positively over to crude oil variance, those in crude oil spill negatively over to natural gas, and those in heating oil spill positively over to natural gas. Furthermore, natural gas reacts with lags to extreme standardized shocks in crude oil and gasoline. Finally, it stems from volatility relationships in Table 2 that heating oil and natural gas are strongly related in volatility, gasoline and crude oil are weakly related and shocks in crude oil do spill over to natural gas.

\section{CONCLUSION}

Shocks in prices of oil products and natural gas have shown to impact the stability of most economies. Such shocks do also impact the formation and the transformation of risk on capital markets. However, these shocks are puzzling in the ways they affect the production tools and the consumption baskets across cities and countries. The gradual under-reaction hypothesis is one of the hypotheses explaining why innovations in prices of petroleum products may affect stock market with lags. We examine in this paper the mechanisms of shock transmission across a spectrum of prices of energy products. We argue that understanding the nature of shock spillovers between such prices may reveal the strongest link among these products. Such a link may be a channel by which oil risk is transferred to rest of the economy. Our findings support the under-reaction hypothesis looking at the relationship between prices of oil products and natural gas.

Our results have two important practical applications. First, the leadership of the price of one product with respect to the price of another product may help hedgers in developing the appropriate timing for the termination of a future contract. Second, hedgers who are exposed to risk associated with prices of oil products may find it beneficial to alter their strategy given the volatility spillovers results which show the nature of such risk as it is formed and transformed across products and markets.

\section{AUTHOR INFORMATION}

Dr. Bernard Ben Sita, Ph.D., is an Assistant Professor of Finance. He received his Ph.D. degree in Finance from Hanken School of Economics in Helsinki in Finland. His research focuses on market microstructure, volatility estimation and energy economics. His research has been published in the Quarterly Review of Economics and Finance, International Review of Financial Analysis, and Energy Policy. E-mail: bernard.bensita@lau.edu.lb (Corresponding author)

Salaheddine S. Abosedra; Ph.D. - Dr. Abosedra is an economist whose areas of expertise include macroeconomic policies in oil based economies and energy economies. He conducted research at the IMF, held a Fulbright Fellow and taught at several universities in the Middle East and the USA. Recently, he spent two years as a Regional Advisor, Macroeconomics Policies at ESCWA, UN. His articles appeared in Applied Financial Economics, Applied 
Energy, and Energy Policy among other journals. He holds a Ph.D. in Economics from the University of Colorado. E-mail: $\underline{\text { salaheddin.abosedra@lau.edu.lb }}$

\section{REFERENCES}

1. Asche, F., Gjolberg, O., Volker, T., 2003, Price relationships in the petroleum market: an analysis of crude oil and refined product prices, Energy Economics, 25, 289-301.

2. Driesprong, G., Jacobsen, B., Maat, B., 2008, Striking oil: Another puzzle? Journal of Financial Economics, 80, 307-327.

3. Ewing, B.T, Malik, F., Ozfidan, O., 2002, Volatility transmission in the oil and natural gas markets, Energy Economics, 2, 525-538.

4. Ferson, W.E., Harvey, C.R., 1993, The risk and predictability of international equity returns, Review of Financial Studies, 6, 527-566.

5. Hamilton, J.D., 2003, What is an oil stock? Journal of Econometrics, 113, 363-398.

6. Hammes, D., Willis, D., 2005, Black gold: the end of bretton woods and the oil price shocks of the 1970s, The Independent Review, 9, 501-511.

7. Han, H., 2010, Asymptotic properties of GARCH-X processes, Working Paper, National University of Singapore.

8. Hwang, S., Satchell, S., 2005, GARCH model with cross-sectional volatility: GARCHX models, Applied Financial Economics, 15, 203-216.

9. Hong, H.G., Stein, J., 2000, Bad news travels slowly, size, analyst coverage and the profitability of momentum strategies, Journal of Finance, 55, 265-295.

10. Hooker, M.A., 1999, Oil and the macro economy revisited, Working Paper, Federal Reserve Board, Chicago.

11. Lamoureux, C.G., Lastrapes, W.D., 1990, Heteroskedasticity in Stock Return Data: Volume versus GARCH Effects, Journal of Finance, 45, 221-29.

12. Lee, K., Ni, S., Ratti, R.A., 1995, Oil shocks and the macroeconomy: the role of price variability, Energy Policy 16, 39-56.

13. Lee, T.K., Zyren J., 2007, Volatility relationship between crude oil and oil products, Atlantic Economic Journal, 35, 97-112.

14. Manera, M., McAleer, M., Grasso, M., 2006, Modelling time-varying conditional correlations in the volatility of Tapis oil spot and forward returns, Applied Financial Economics, 16, 525-533.

15. Ng, V.K., Pirrong, S.C., 1996, Price dynamics in refined petroleum spot and futures markets, Journal of Empirical Finance, 2, 359-388.

16. Pindyck, R.S., 2004, Volatility in natural gas and oil markets, Journal of Energy and Development, Autumn, 1-19.

17. Staikouras, S., 2006, Testing the stabilization hypothesis in the UK short-term interest rates: Evidence from a GARCH-X model, Quarterly Review of Economics and Finance 46, 169-189.

18. Wilhelmsson, A., 2006, Garch forecasting performance under different distribution assumptions, Journal of Forecasting, 25, 561-578. 